\title{
Galvanic coupling effects on the corrosion behavior of the 6061 aluminum alloy used in
} research nuclear reactors

Mariana X. Milagre ${ }^{1}$; Uyime Donatus ${ }^{2}$, Rejane Maria P. Silva ${ }^{1}$; Abenchara M. Betancor-Abreu ${ }^{3}$, Oscar M. Prada Ramirez ${ }^{4}$; Caruline S. C. Machado ${ }^{1}$; João Victor S. Araujoㅁ, Ricardo M. Souto ${ }^{3}$; Isolda Costa ${ }^{1}$

${ }^{1}$ Instituto de Pesquisas Energéticas e Nucleares - IPEN/CNEN - Av. Prof. Lineu Prestes, 2242

$$
\text { - São Paulo - Brazil }
$$

${ }^{2}$ Brunel Centre for Advanced Solidification Technology (BCAST) - Brunel University - Uxbridge, Middlesex UB8 3PH, United Kingdom

${ }^{3}$ Universidad de La Laguna - E-38207 - La Laguna - Tenerife - Canary Islands-Spain ${ }^{4}$ Universidade de São Paulo, Departamento. de Engenharia Metalúrgica e de Materiais, 05508030 - São Paulo - Brazil

\begin{abstract}
The 6061 alloy is used in different thermomechanical conditions in research nuclear reactors. Nuclear fuel plates are manufactured by the picture frame technique (PFT) and the 6061 alloy is used as cladding for the nuclear fuel "sandwiches". After the process, these nuclear plates are placed in a case composed of 6061-T6 alloy. In this work, the galvanic effects of coupling the 6061 alloy in the T6 and PFT conditions on the corrosion behavior was investigated in solutions of different chloride contents. The results showed that galvanic corrosion was favored due to the different microstructural features related to these two thermomechanical conditions of the 6061 alloy. The 6061 alloy in the PFT condition was cathodic to the alloy in the T6 condition. Local electrochemical techniques were useful in characterizing the electrochemical behavior of the coupled alloys.
\end{abstract}

Key-words: aluminum alloys, corrosion, local electrochemical techniques 


\section{Introduction}

The $6061 \mathrm{Al}-\mathrm{Mg}$-Si alloy has been used in the structure of fuel plates for research nuclear reactors due to its good mechanical properties, corrosion resistance, radiation tolerance and low neutron cross-section [1-5]. This alloy is used in nuclear research reactors in different thermomechanical conditions, in the T6 temper condition and in a specific temper related to nuclear fuel plates manufacturing, namely picture frame technique (PFT).

The thermomechanical history of the commercially extruded T6 temper condition comprises solution heat treatment and artificially aging of the alloy at $175^{\circ} \mathrm{C}$ for $10 \mathrm{~h}-20 \mathrm{~h}$, in order to favor $\beta$ " phase precipitation, which is responsible for hardening of this alloy $[6,7]$. The PFT process, on the other hand, involves steps of heating, hot working and cold working of the commercial $O$ temper condition. The 6061-O alloy is the annealed temper condition. During the PFT process, plates of 6061-O alloy are heated and hot/cold rolled in order to produce plates with suitable dimensions for the nuclear fuel plates. Figure 1 presents a flow chart of the stages in the PFT process. After this process, the 6061 clad presents a different microstructure in relation to the 6061-T6 temper condition used in the nuclear fuel plate case (Figure 2). Nuclear fuel plates are placed in a case of 6061-T6 and between the plates, there are gaps where a flux of coolant (pure water) passes.

The effect of thermomechanical treatments on the corrosion behavior of $\mathrm{Al}$ alloys has been extensively reported [8-11]. According to Zeid et al. [9], the $\mathrm{Q}\left(\mathrm{Mg}_{2} \mathrm{Si}\right)$ phase formation in the 6061 alloy, after natural and artificial aging, can assume different orientations and this can affect the corrosion behavior of the alloy. Kairy et al. [10] showed that depending on the continuity and type of grain boundary phases, which is dependent on the chemical composition and aging parameters, the severity of intergranular corrosion (IGC) associated with 6XXX series aluminum alloy varies. In another study, the authors [11] reported that susceptibility to metastable pitting of 6XXX Al series is reduced with the refinement of precipitates.

Galvanic corrosion occurs when dissimilar metals with different potentials are coupled and exposed to corrosive environments. One of the metals acts as the anode, corroding faster, while the other acts as the cathode, corroding at a slower rate [12,13]. Galvanic coupling of dissimilar nuclear materials has been reported [14-17]. However, reports on galvanic couplings effects of similar materials are scarce.

The galvanic effect concept can be extended to similar materials with different microstructural features. Galvanic corrosion associated with welded materials, due to different microstructural features observed according to the welding zones, are reported in the literature [18-21]. In general, this behavior is associated with grain refinement and phase dissolution and/or phase coarsening [22,23]. Kermanidis et al. [21] showed that 6XXX alloy with different temper conditions, 
when coupled by welding can show different corrosion behavior in the welded zone due to microstructural modifications. Lim et al. [24] also reported different corrosion behavior for the weldment of the 6061-T651 alloy due to its different microstructural features along the weldment. The authors showed that a refined microstructure presents higher corrosion resistance than that of the parent material which is less refined.

Despite the slow corrosion rate of $\mathrm{Al}$ in pure water, the microstructural modification in the 6061 alloy due to the PFT process is a suitable condition for corrosion development if the purity of the coolant is not controlled. In the case of the nuclear fuel plates and the nuclear fuel case, both materials, 6061-T6 and PFT, are in electrical contact favoring the establishment of galvanic coupling. Also, since the fuel plates are stored in research nuclear pool for years, if the passive oxide layer is damaged in the environment a corrosion process would be initiated.

The micro-galvanic coupling mechanism has been extensively reported as the main corrosion mechanism for localized corrosion in Al alloys [25-30]. This kind of corrosion is related to potential differences between second phase particles and the matrix, where the second phase can assume higher (cathodic) or lower (anodic) potentials in relation to the Al matrix. The 6061 alloy presents Mg-enriched and Fe-enriched second phase particles. The Mg-enriched particles are anodic, whereas the Fe-enriched ones are cathodic in relation to the matrix. Moreover, nano-sized Mg-Si enriched phases at the grain boundaries favor intergranular corrosion [9,29-31]. According to the literature [32], anodizing could be used as a surface treatment to prevent corrosion in nuclear materials by the growth of $\mathrm{Al}_{2} \mathrm{O}_{3}$ on the surfaces of the aluminum alloys [32]. However, if the substrate is exposed and the purity of the coolant is not well controlled, the aluminum alloy will corrode.

To the best of the knowledge of the authors, there are no reports in the literature on the macrogalvanic coupling effects between the AA6061-T6 and AA6061 in the PFT condition. In this work, the effect of macro galvanic coupling between the 6061 alloy in the T6 and PFT temper conditions on their corrosion resistance was investigated. The coupled alloys were tested in an aggressive test solution in order to accelerate the corrosion process. The coupling effects were evaluated by means of conventional and local electrochemical techniques and the results were correlated with the microstructural features of each alloy.

\section{Experimental}

\section{$\underline{\text { Materials }}$}

In this work, samples of the 6061 alloy (Al 89.9 wt\%, Cr 0.10 wt $\%$, Cu $0.22 \%$, Fe 0.20 wt $\%$, Mg $0.90 \mathrm{wt} \%$, Mn $0.05 \mathrm{wt} \%$, Si $0.13 \mathrm{wt} \%$ and $\mathrm{Zn} 0.02 \mathrm{wt} \%)$, with the thermomechanical treatments 
presented in Table 1, were galvanically coupled in order to evaluate the effect of coupling on their corrosion behaviour. Table 1 shows a brief description of each 6061 alloy condition.

Table1 - Summary of the thermomechanical conditions of the 6061 alloy used in this study.

\begin{tabular}{c|c}
\hline Sample & Description \\
\hline T6 & Commercial temper condition. (1) Solution heat treatment; (2) artificial aging. \\
\hline PFT & $\begin{array}{r}\text { Nuclear fuel plates clad manufacturing process; (1) Solution heat treatment; (2) } \\
\text { hot working; (3) Solution heat treatment; (4) Cold working. }\end{array}$ \\
\hline
\end{tabular}

\section{Samples preparation and microstructural characterization}

The surface of the samples for exposure to the test solution was sequentially ground with $\mathrm{SiC}$

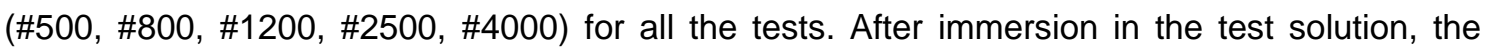
exposed surface was examined under an optical microscope and a scanning electron microscope (SEM) using a Hitachi TM 3000 with an incident beam of $15 \mathrm{keV}$. Microhardness measurements were carried out by means of a Buehler macrohardness tester using $200 \mathrm{gf}$ for a dwell time of 10 $\mathrm{s}$, and 30 random measurements were recorded. Energy dispersive X-ray Spectroscopy (EDX) maps from the surfaces of the samples were obtained using a FEG-SEM microscope Jeol JSM$6701 \mathrm{~F}$.

\section{Conventional electrochemical techniques}

Open circuit potential (OCP) was obtained using an AUTOLAB PGSTAT potentiostat controlled by NOVA 2.1 software. The experiments were carried out using a three-electrode cell configuration. Samples of the 6061 alloy with the two temper conditions were used as working electrodes. The exposed surface of the samples corresponded to $0.09 \mathrm{~cm}^{2}$. Platinum wire was used as the counter electrode and an $\mathrm{Ag} / \mathrm{AgCl} / \mathrm{KCl}$ (sat) electrode as the reference electrode. The experiments were performed at room temperature $\left(23 \pm 2^{\circ} \mathrm{C}\right)$ for $4 \mathrm{~h}$ using a solution composed of $0.6 \mathrm{~mol} \mathrm{~L}^{-1}$ of $\mathrm{NaCl}$.

\section{Agar gel visualization test}

The anodic and cathodic behaviors of the alloys were evaluated using agar gel visualization test. The gel was prepared using a mixture prepared by the addition of $3 \mathrm{~g}$ of agar and $7 \mathrm{~mL}$ of universal indicator to $100 \mathrm{~mL}$ of a boiling $0.6 \mathrm{~mol} \mathrm{~L}^{-1} \mathrm{NaCl}$ solution. Samples of the 6061-T6 and 6061-PFT were electrically connected with a copper tape and embedded in cold epoxy resin. 


\section{Scanning vibrating electron technique}

Scanning vibrating electron technique (SVET) was carried out using an Applicable Electronics Equipment. A vibrating probe of $\mathrm{Pt} / \mathrm{Ir}$ wire insulated with paralene $C$ was used. The microelectrode was platinized in order to produce a spherical platinum black deposit of $20 \mu \mathrm{m}$ diameter at the tip. The frequency of the electrode vibration was $200 \mathrm{~Hz}$ for vibration $\mathrm{X}$, and $70 \mathrm{~Hz}$ for vibration $\mathrm{Y}$ with amplitude of $20 \mu \mathrm{m}$. Scans were carried out over the galvanically coupled system at a height of $150 \mu \mathrm{m}$ from the sample. The experiments were carried out in a solution with $0.05 \mathrm{~mol} \mathrm{~L}^{-1}$ of $\mathrm{NaCl}$ at room temperature $\left(22 \pm 2^{\circ} \mathrm{C}\right)$.

\section{Local electrochemical impedance spectroscopy (LEIS)}

Local electrochemical impedance spectroscopy (LEIS) experiments were carried out using an Ametek ${ }^{\circledR}$ VS-LEIS system, controlled by the VerScan® Software. The scanned area was $25 \mathrm{~mm}^{2}$ and the maps were obtained at a frequency of $5 \mathrm{~Hz}$ with an amplitude of $20 \mathrm{mV}$ and a step size of $200 \mu \mathrm{m}$ in a height of $300 \mu \mathrm{m}$ from the sample surface. The experiments were performed in $0.005 \mathrm{~mol} \mathrm{~L}^{-1}$ of $\mathrm{NaCl}$, at room temperature $(22 \pm 2)^{\circ} \mathrm{C}$. $\mathrm{An} \mathrm{Ag} / \mathrm{AgCl}$ electrode was used as reference and a Pt ring was used as counter electrode. Admittance maps of coupled sample were acquired after $2 \mathrm{~h}$ of exposure to the solution. Samples with the two temper conditions were coupled by a copper wire and embedded in epoxy resin for measurements.

\section{Scanning electrochemical microscopy (SECM)}

Scanning electrochemical microscopy (SECM) was performed using a Sensolytics (Bochum, Germany). The measurement was conducted in the competition mode [33-39], with the molecular oxygen content being monitored from its reduction at the tip polarized at $-0.70 \mathrm{~V} \mathrm{Ag} / \mathrm{AgCl}$ (reaction 1):

$$
\mathrm{O}_{2}+2 \mathrm{H}_{2} \mathrm{O}+4 \mathrm{e}^{-} \rightarrow 4 \mathrm{OH}^{-}
$$

At this potential, the reduction of oxygen occurs under diffusion and in this measurement the $\mathrm{Pt}$ microelectrode and the surface compete for the oxygen dissolved in solution $[36,38,39]$. Positioning of the Pt tip was performed by recording the z-approach curves over each coupled sample using the redox competition SECM mode. A change in the profile of the limiting current was obtained close to the surface, and the optimal distance obtained was $20 \mu \mathrm{m}$ above it with a scan rate of $50 \mu \mathrm{m} \mathrm{s}^{-1}$. In order to obtain a better measurement resolution the scanned are was $250 \times 250 \mu \mathrm{m}^{2}$. An Ag/AgCl electrode was used as a reference, and platinum wire was used as a counter. The Pt tip was $10 \mu \mathrm{m}$ in diameter. The experiments were performed in $0.05 \mathrm{~mol} \mathrm{~L}^{-1}$ $\mathrm{NaCl}$ solution at room temperature $\left(22 \pm 2{ }^{\circ} \mathrm{C}\right)$ in neutral $\mathrm{pH}$. The oxygen current maps were 
obtained above the surface of each temper condition surface coupled by electrical contact wires and embedded in epoxy resin.

\section{Results and Discussion}

Time evolution of the open circuit potential (OCP) measurements for the 6061 alloy in either T6 temper or picture frame technique (PFT) conditions were monitored during the first $4 \mathrm{~h}$ of immersion in $0.6 \mathrm{~mol} \mathrm{~L}^{-1} \mathrm{NaCl}$ solution, Figure 3. The samples were analyzed both in isolation and when galvanically coupled. In the first hour of immersion, the different samples presented similar OCP values; however, with time, a difference of around $50 \mathrm{mV}$ between the samples was established. The OCP is dependent on the chemical composition and temper condition. As the chemical composition of the samples is the same, the increased potential of the PFT condition in relation to T6 temper is related to the microstructural modification that occurred during the manufacturing process. The sequence of heating, hot and cold rolling processes are responsible for the modifications in the microstructural features of the 6061 alloy. Consequently, different electrochemical behaviors were related to the T6 and PFT conditions. The lower potentials related to the T6 condition means that it will act as an anode when galvanically coupled to the PFT sample. The OCP curve corresponding to the coupled samples shows an OCP with intermediate values between those of the isolated T6 and TFP conditions. The fact that the OCP rapidly reached fairly stable values for the coupled condition suggests faster kinetics of the corrosion process in this condition than for the T6 and PFT conditions in isolation.

The test solution with high chloride content was highly aggressive for both conditions. Figure 4(a) and Figure 5(a) show pits evenly distributed in both types of tested samples, the T6 and PFT exposed surfaces, respectively. However, the pit morphology differs for both conditions. In addition, corrosion propagation in the T6 condition was intergranular, as observed by the high magnification images of the T6 condition, Figure 4(b-c); and intragranular for the PFT condition, as observed from the high magnification image, Figure $5(b)$. The exposed surface of the coupled samples was examined after immersion, Figure 6 . It is interesting to note that the number of pits (inside yellow circles) per area increased for the T6 sample in the galvanically coupled case, whereas it decreased in the PFT sample. This is explained by the fact that the PFT sample is the cathode being protected during galvanic coupling.

The corrosion behavior in the 6061 alloy is associated with the second phases which are Fe-Si and Mg-Si enriched. Micrometric particles, Figure 7(a), are formed during casting and are related to the low solubility of some elements in the Al matrix. The Fe-enriched particles are cathodic in relation to the matrix while the Mg-enriched ones are initially anodic to the matrix. Despite their contribution to the corrosion of the 6061 alloy, the micrometric particles are not affected by the PFT process. On the other hand, the nano-sized $\mathrm{u}\left(\mathrm{Mg}_{2} \mathrm{Si}\right)$ phase precipitation is affected by the 
thermomechanical process. The main phase responsible for the strengthening of the 6061 alloy is the $\beta$ " phase. Since the T6 temper is a peak aged condition, a higher density of the $\square^{\prime \prime}$ phase is expected, as the microhardness measurements show, Figure 7(b). The microhardness related to the PFT condition is about twice lower, which can be explained by phase dissolution and coarsening. Therefore, the lower values of OCP for the T6 condition, and as consequence, the higher susceptibility to corrosion can be associated with its higher amount of $\beta "$ phase in relation to the PFT condition.

The effect of galvanic coupling between the T6 and PFT samples was easily identified by the agar gel visualization test. According to Figure 8, when the PFT and T6 alloys are exposed to the gel in isolation, both alloys present well-defined acidified regions, which are related to pitting corrosion. However, when the alloys are galvanically coupled, the PFT sample is cathodically protected by the $T 6$ sample. Acidified regions related to severe pit growth were only observed on the T6 sample corroborating the anodic behavior of this sample in the galvanic pair.

SVET maps of each of the coupled alloy tested were obtained by scanning vibrating electrode technique (SVET) after $2 \mathrm{~h}$ of immersion in $0.05 \mathrm{~mol} \mathrm{~L}^{-1} \mathrm{NaCl}$ solution, Figure 9a. The results corroborates with those from the agar test. According to the results obtained, when the samples are coupled, anodic behaviour was related to the T6 condition, whereas the PFT condition presented a cathodic behavior. As observed by the images in Figure $9 \mathrm{~b}$ and Figure $9 \mathrm{c}$, the anodic behavior was related to localized attack.

The corrosion mechanism was also evaluated by local electrochemical impedance spectroscopy (LEIS) technique after $2 \mathrm{~h}$ of immersion in $0.005 \mathrm{~mol} \mathrm{~L}^{-1} \mathrm{NaCl}$ solution, Figure 10 . The results are in accordance with the previous ones. Galvanic coupling was observed between the T6 and PFT samples and the T6 sample presented higher electrochemical activity than the PFT sample. This result points to the importance of controlling the purity of the coolant to avoid galvanic effects between parts of the nuclear fuel elements made with 6061 alloy subjected to different thermomechanical conditions and in contact. Maps are plotted in terms of admittance (inverse of impedance) since at low frequencies it correlates directly with corrosion rate. The 6061-T6 sample was more active than the PFT one and it was also more susceptible to pitting corrosion, as indicated in the maps of Figure 10.

Scanning electrochemical microscopy (SECM) was also carried out after $2 \mathrm{~h}$ of immersion in 0.05 $\mathrm{mol} \mathrm{L}^{-1} \mathrm{NaCl}$ solution, Figure 11. This technique is useful in revealing the nature of the reactions occurring over the surface. The tip was polarized to the oxygen reduction potential $(-0.70 \mathrm{~V}$ vs $\mathrm{Ag} / \mathrm{AgCl}$ ). The size of the containing tested galvanically coupled T6 / PFT was reduced in the SECM for both coupled surfaces, in relation to the other local electrochemical techniques to improve measurement resolution. As observed, from the SECM maps, the oxygen reduction current measured at the tip was smaller above the T6 to the PFT sample. Since the tip is polarized 
to the oxygen reduction potential, the surface related to higher oxygen currents (blue) corresponds to the anodic one, because it does not show significant consumption of dissolved oxygen from the adjacent electrolyte. Therefore, aluminum dissolution (reaction 2) predominates at the $\mathrm{T} 6 \mathrm{Al}$ alloy.

$$
A l \rightarrow A l^{3+}+3 e^{-}
$$

On the other hand, on the exposed surface of the PFT alloy, depletion in oxygen was observed (red). This occurs due to oxygen consumption by the cathodic reaction (equation 1). Consequently, the PFT sample acts as cathode.

Galvanic corrosion is characterized by the electrical contact of metals with different potentials when they are exposed to aggressive environment. Thus, galvanic coupling originates preferential and accelerated dissolution of the less noble metal, acting as anode, while the corrosion rate of the metal acting as cathode is reduced. Pitting corrosion in the 6XXX aluminum alloys correlates well with the activities of Mg-Si particles $[29,31,40]$. Furthermore, as observed by this work, it is dependent on the thermomechanical processing. The 6061 peak aged condition, T6, is associated with high strength and, consequently, with a high content of $\beta$ " phase. The 6061 alloy in the PFT condition presented lower strength than the T6 sample, likely due to the dissolution of the anodic $\beta$ " phase and other possible Mg-Si particles. This process, in turn, improved the corrosion behavior of the PFT 6061 alloy.

Pitting corrosion related to the peak aged condition of the 6XXX alloys has been associated with intergranular corrosion propagation $[10,11]$. The presence of anodic phases at the grain boundaries and precipitate free zones at the vicinities of them lead to intergranular corrosion in the 6XXX series alloys. As observed by SEM micrographs, Figure 4(c) and Figure 5(b), the grain boundaries are more active for the 6061-T6 than for the PFT condition, indicating that precipitation of anodic phases at the grain boundaries is favored in the 6061-T6. Additionally, when the plates of 6061 T6 and PFT are coupled, galvanic corrosion is promoted due to the differences explained by the higher content of $\beta$ " phase in the peak aged T6 condition, and to MgSi phase dissolution during the PFT process, Figure 7(b). The higher content of Mg-Si particles related to the T6 condition decreases it potential in relation to the PFT, and galvanic coupling is promoted between these alloys. As the $\beta$ " phase is related to pitting corrosion in the 6XXX series alloy, the higher content of preferential sites for localized corrosion favors the dissolution of the T6 alloy. Additionally, the fast kinetics of dissolution process release eletrons to the cathodic sites. Despite the cathodic Fe-Si micrometric particles in T6, the cathodic surface available is not sufficient to consume the released electrons, that migrate to the PFT, due the difference of potential. At the PFT surface, the lower content of Mg-Si particles increases the available cathodic surface for the oxygen reduction. Therefore, the PFT surface act as a cathode and the attack in this alloy is related to local alkalinization (despite the presence of a few pits, as observed in Figure 6) as a result of the reduction reaction. A schematic diagram proposed for the corrosion mechanism of 
the the T6 / PFT coupled 6061 Al alloy is shown in Figure 12. The results from localized electrochemical techniques support the mechanism proposed. The observation by SVET showed higher corrosion currents associated with the T6 condition. Moreover, the higher oxygen consumption on the PFT sample also indicates higher reduction activity over the PFT surface. Finally the admittance maps obtained at $5 \mathrm{~Hz}$ differentiated the kinetics of the electrochemical processes and higher pitting susceptibility related to the T6 condition compared to the PFT alloy. The possibility of galvanic coupling between the 6061 alloy with different thermomechanical treatment, as presented in this study, even in solution of low chloride content, as the one used ( $0.005 \mathrm{~mol} \mathrm{~L}^{-1}$ of $\mathrm{NaCl}$ solution), shows the necessity of a severe control of the coolant purity in contact with these alloys.

\section{Conclusions}

The picture frame technique (PFT) used in the processing of nuclear fuel elements affected the properties of the $6061 \mathrm{Al}$ alloy, including its corrosion behavior. The reduction in " phase content during the PFT process decreased the corrosion susceptibility of the 6061 alloy and increased the open circuit potential. Galvanic coupling between parts of the nuclear fuel plates cladding (6061-PFT) and the nuclear fuel case (6061-T6) is favored due to the microstructural modifications induced by the PFT process. Galvanic coupling was identified by the various techniques used with different chloride contents. The results from local electrochemical techniques are in accordance with the other tests used and showed that the nuclear fuel plates cladding (6061-PFT) acts as a cathode, when coupled to the nuclear fuel case (6061-T6), which acts as an anode.

\section{Acknowledgments}

The authors acknowledge CNEN for the grants of M.X. Milagre (SEI 01342.002357/2019-32), CAPES for the grants of C.S.C. Machado (88882.333459/2019-01), FAPESP for financial support (2013/12323-6) and the grant of R. Silva (Proc. 2018/06880-6), and the Spanish Ministry of Economy and Competitiveness (MINECO, Madrid, Spain) and the European Regional Development Fund (Brussels, Belgium) under grant CTQ2016-80522-P. Acknowledgements are also due to Universidad de La Laguna, (Dr. Ricardo M. Souto), for SECM and SVET analysis and to the Polytechnic School of São Paulo University (PMT/USP), Dr. Hercilio G. de Melo, for the LEIS analysis. Also, to Dr. José A. B. de Souza from the Nuclear Fuel Center of the Instituto de Pesquisas Energéticas e Nucleares (CNN/ IPEN) for providing the material used in this study.

\section{References}

[1] D. Féron, Overview of nuclear materials and nuclear corrosion science and engineering, Nucl. Corros. Sci. Eng. (2012) 31-56. 
[2] American Society for Materials, ASM Handbook Properties and selection: Nonferrous alloys and Special-purpose Materials, 2001.

[3] R.H. Howard, R.C. Gallagher, K.G. Field, Mechanical performance of neutron-irradiated dissimilar transition joints of aluminum alloy 6061-T6 and 304L stainless steel, J. Nucl. Mater. 508 (2018) 348-353.

[4] A.F.F. Giacobone, S.A. Rodriguez, A.L. Burkart, R.A. Pizarro, Microbiological induced corrosion of AA 6061 nuclear alloy in highly diluted media by Bacillus cereus RE 10, Int. Biodeterior. Biodegradation. 65 (2011) 1161-1168.

[5] S.M. de C. Fernandes, O.V. Correa, J.A.B. de Souza, R.A. Antunes, N.B. de Lima, L. Enkataraman Ramanathan, Effect of processing on microstructure and corrosion mitigating properties of hydrotalcite coatings on AA6061 Alloy, Mater. Res. 18 (2015) 1203-1208.

[6] S. Pogatscher, H. Antrekowitsch, H. Leitner, T. Ebner, P.J. Uggowitzer, Mechanisms controlling the artificial aging of Al-Mg-Si Alloys, Acta Mater. 59 (2011) 3352-3363.

[7] S.J. Andersen, H.W. Zandbergen, J. Jansen, C. Tr/Eholt, U. Tundal, O. Reiso, The crystal structure of the $\beta^{\prime \prime}$ phase in Al-Mg-Si alloys, Acta Mater. 46 (1998) 3283-3298. doi:10.1016/S1359-6454(97)00493-X.

[8] M.S. Oskooie, H. Asgharzadeh, S. Sadighikia, M. Salehi, Significant corrosion resistance in an ultrafine-grained Al6063 alloy with a bimodal grain-size distribution through a selfanodic protection mechanism, Metals (Basel). 6 (2016), 307.

[9] E.F. Abo Zeid, Mechanical and electrochemical characteristics of solutionized AA 6061, AA6013 and AA 5086 aluminum alloys, J. Mater. Res. Technol. 8 (2019) 1870-1877.

[10] S.K. Kairy, P.A. Rometsch, C.H.J. Davies, N. Birbilis, On the Intergranular corrosion and hardness evolution of 6XXX series Al alloys as a function of Si:Mg ratio, Cu content, and aging condition, Corrosion. 73 (2017) 1280-1295.

[11] S.K. Kairy, P.A. Rometsch, C.H.J. Davies, N. Birbilis, The influence of copper additions and aging on the microstructure and metastable pitting of Al-Mg-Si alloys, Corrosion. 71 (2015) 1304-1307.

[12] J. Kruger, Corrosion of metals: Overview, in: Encycl. Mater. Sci. S. Mahajan, K.H.J. Buschow, R. Cahn, M.C. Flemings, B. Ilschner, E.J. Kramer, P. Veyssiere (Eds.), Technol., Pergamon, Oxford, 2001: pp. 1701-1706.

[13] R.P. Frankenthal, J.D. Sinclair, Corrosion of electronic materials and devices, in: Encycl. Mater. Sci. Technol.S. Mahajan, K.H.J. Buschow, R. Cahn, M.C. Flemings, B. Ilschner, E.J. Kramer, P. Veyssiere (Eds.), Pergamon, Oxford, 2001: pp. 2638-2644.

[14] H.J. Zhang, Effect of bacterial biofilm on corrosion of galvanically coupled aluminum and stainless steel alloys under conditions simulating wet storage of spent nuclear fuel, Corrosion. 55 (1999) 924-936.

[15] V. Kain, K. Agarwal, P.K. De, P. Seetharamaih, Environmental degradation of materials during wet storage of spent nuclear fuels, J. Mater. Eng. Perform. 9 (2000) 317-323. 
[16] Y.M. Han, D. Gallant, X.G. Chen, Galvanic corrosion associated with Al-B ${ }_{4} C$ composites/SS304 and Al-B4C composites/AA6061 couples in $\mathrm{NaCl}$ and $\mathrm{H}_{3} \mathrm{BO}_{3}$ solutions, Electrochim. Acta. 94 (2013) 134-142.

[17] J. Ahlström, J. Tidblad, B. Sandberg, L. Wadsö, Galvanic corrosion properties of steel in water saturated concrete, Mater. Corros. 66 (2015) 67-75.

[18] U. Donatus, J.V. de Sousa Araujo, C. de Souza Carvalho Machado, N.V. Vardhan Mogili, R.A. Antunes, I. Costa, The effect of manufacturing process induced near-surface deformed layer on the corrosion behaviour of AA2198-T851 Al-Cu-Li alloy, Corros. Eng. Sci. Technol. (2018) 1-11.

[19] M. X. Milagre, U. Donatus, N. V. Mogili, R. M. P. Silva, B. V. G. de Viveiros, V. F. Pereira, R. A. Antunes, C. S. C. Machado, J. V. S. Araujo, I. Costa, Galvanic and asymmetry effects on the local electrochemical behavior of the 2098-T351 alloy welded by friction stir welding, J. Mater. Sci. Technol. 45 (2020) 162-175.

[20] C. Machado, U. Donatus, M. Xavier Milagre, N. Mogili, R. Giorjão, R. Klumpp, J.V. Araujo, R. Ferreira, I. Costa, Correlating the modes of corrosion with microstructure in friction stir welded AA2198-T8 alloy in aqueous hydrogen peroxide-chloride medium, Corrosion. 75 (2019) 628-640.

[21] A.T. Kermanidis, A.D. Zervaki, V. Modas, A.N. Chamos, S.G. Pantelakis, Fatigue performance of pre-corroded 6xxx aluminum alloy laser beam welds with dissimilar heat treatment, Procedia Eng. 74 (2014) 22-26. doi:10.1016/j.proeng.2014.06.217.

[22] T. Burleigh, F. Bovard, R. Rennick, Technical Note: Corrosion Potential for Aluminum Alloys Measured by ASTM G 69, Corrosion. 49 (1993) 683-685.

[23] R. Khatami, A. Fattah-alhosseini, M.K. Keshavarz, Effect of grain refinement on the passive and electrochemical behavior of 2024 Al alloy, J. Alloys Compd. 708 (2017) 316-322. doi:10.1016/j.jallcom.2017.03.031.

[24] S. Lim, S. Kim, C.-G. Lee, S. Kim, Stress corrosion cracking behavior of frictionstirwelded Al 6061-T651, Metall. Mater. Trans. A. 36 (2005) 1977-1980.

[25] C. Blanc, A. Freulon, M.C. Lafont, Y. Kihn, G. Mankowski, Modelling the corrosion behaviour of Al2CuMg coarse particles in copper-rich aluminium alloys, Corros. Sci. 48 (2006) 3838-3851.

[26] G. O. Ilevbare, O. Schneider, R.G. Kelly, J.R. Scully, G.O. Ilevbare, J.R. Scully, R.G. Kelly, In situ confocal laser scanning microscopy of AA 2024-T3. Corrosion Metrology, J. Electrochem. Soc. 151 (2004) 453-464.

[27] L. Lacroix, C. Blanc, N. Pébère, B. Tribollet, V. Vivier, Localized approach to galvanic coupling in an aluminum-magnesium system, J. Electrochem. Soc. 156 (2009) C259C265.

[28] J.-B. Jorcin, C. Blanc, N. Pébère, B. Tribollet, V. Vivier, Galvanic coupling between pure copper and pure aluminum: Experimental approach and mathematical model , J. Electrochem. Soc. 155 (2008) C46-C51. 
[29] C. Blanc, G. Mankowski, Susceptibility to pitting corrosion of 6056 aluminium alloy, Corros.Sci. 39 (1997) 949-959.

[30] C. Blanc, G. Mankowski, Pit propagation rate on the 2024 and 6056 aluminium alloys, Corros. Sci. 40 (1998) 411-429.

[31] V. Guillaumin, G. Mankowski, Localized corrosion of 6056 T6 aluminium alloy in chloride media, Corros. Sci. 42 (2000) 105-125.

[32] E. Shaber, G. Hofman, Corrosion Minimization For Research Reactor Fuel, (2005).

[33] R.M.P. da Silva, M.X. Milagre, L.A. de Oliveira, U. Donatus, R.A. Antunes, I. Costa, The local electrochemical behavior of the AA2098-T351 and surface preparation effects investigated by scanning electrochemical microscopy, Surf. Interface Anal. 51 (2019) 982-992.

[34] A.G. Marques, J. Izquierdo, R.M. Souto, A.M. Simões, SECM imaging of the cut edge corrosion of galvanized steel as a function of pH, Electrochim. Acta. 153 (2015) 238245.

[35] R.M. Souto, L. Fernández-Mérida, S. González, Secm imaging of interfacial processes in defective organic coatings applied on metallic substrates using oxygen as redox mediator, Electroanalysis. 21 (2009) 2640-2646. doi:10.1002/elan.200900232.

[36] R.M. Souto, Y. González-Garciía, S. González, In situ monitoring of electroactive species by using the scanning electrochemical microscope. Application to the investigation of degradation processes at defective coated metals, Corros. Sci. 47 (2005) 3312-3323.

[37] U. Donatus, R.M.P. Da Silva, J.V.D.S. Araujo, M.X. Milagre, C.P. De Abreu, C.D.S.C. MacHado, I. Costa, Macro and microgalvanic interactions in friction stir weldment of AA2198-T851 alloy, J. Mater. Res. Technol. 8 (2019) 6209-6222.

[38] S. Thomas, J. Izquierdo, N. Birbilis, R.M. Souto, Possibilities and Limitations of Scanning Electrochemical Microscopy of Mg and Mg Alloys, Corrosion. 71 (2015) 171-183.

[39] A.C. Bastos, A.M. Simões, S. González, Y. González-García, R.M. Souto, Imaging concentration profiles of redox-active species in open-circuit corrosion processes with the scanning electrochemical microscope, Electrochem. Commun. 6 (2004) 1212-1215. doi:10.1016/j.elecom.2004.09.022.

[40] F. Eckermann, T. Suter, P.J. Uggowitzer, A. Afseth, P. Schmutz, The influence of MgSi particle reactivity and dissolution processes on corrosion in $\mathrm{Al}-\mathrm{Mg}-\mathrm{Si}$ alloys, Electrochim. Acta. 54 (2008) 844-855. 


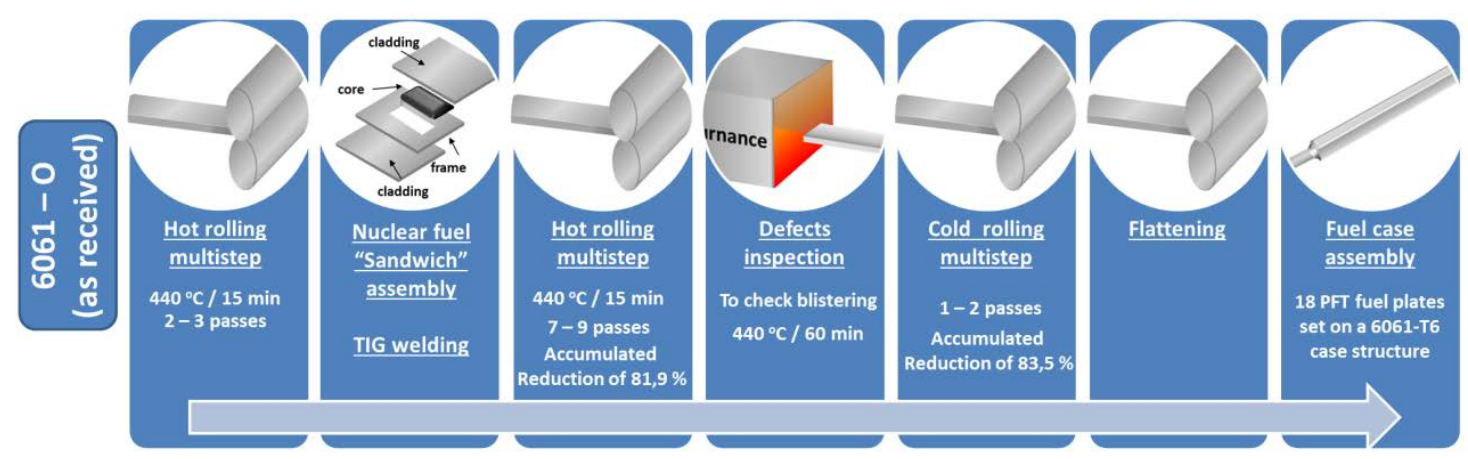

Figure 1 - Flow chart of the picture frame technique (PFT) process.

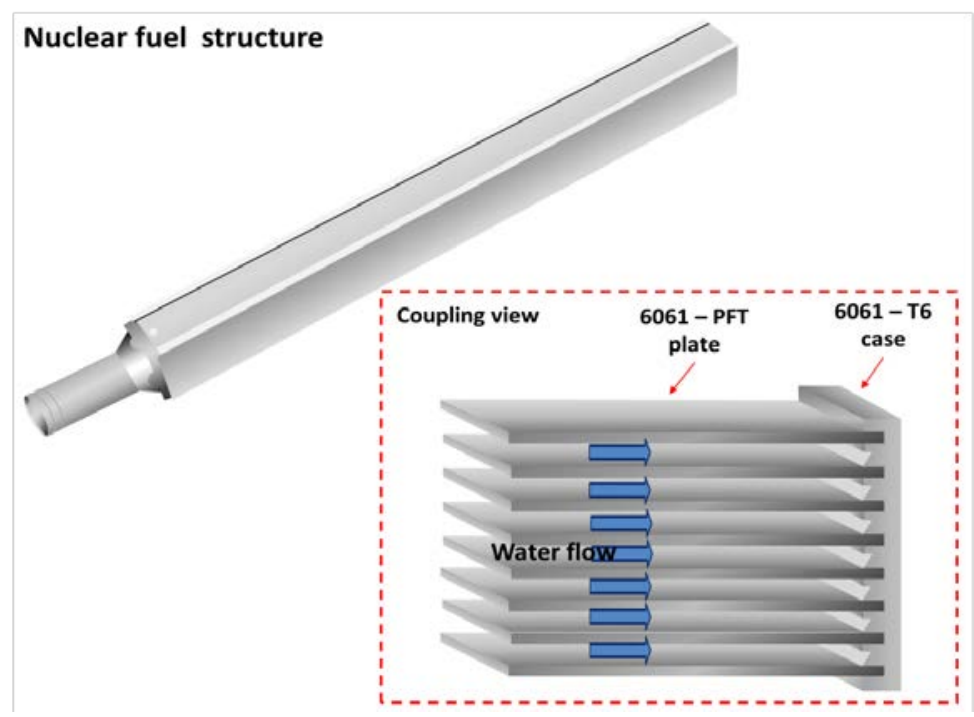

Figure 2 - Schematic diagram of the nuclear fuel case structure showing the coupling between the nuclear plates manufactured by the PFT process and the 6061-T6 alloy. 


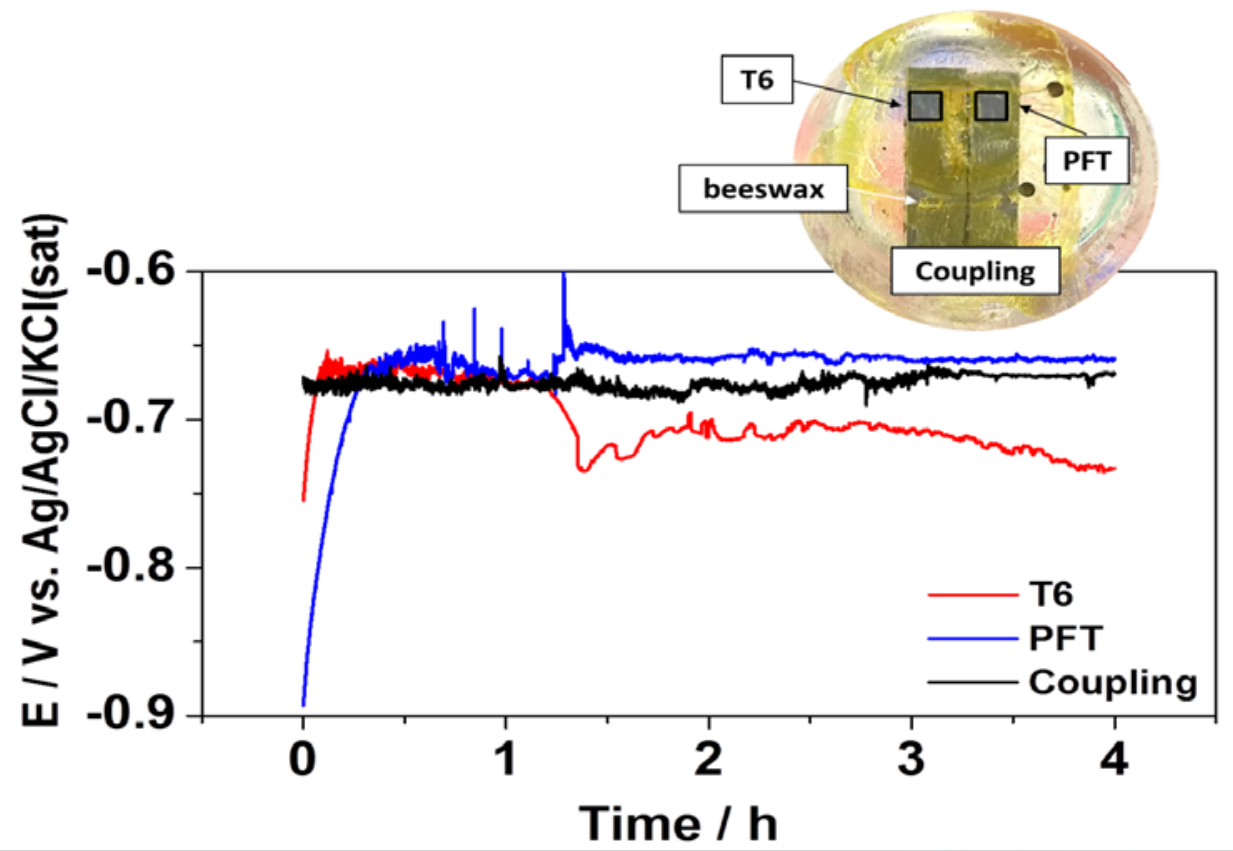

Figure 3 - Open circuit potential curves obtained during $4 \mathrm{~h}$ exposure in $0.6 \mathrm{~mol} \mathrm{~L}^{-1} \mathrm{NaCl}$ solution for the 6061 Al-alloy in T6 commercial temper condition, picture frame technique (PFT) process condition and the coupled T6 / PFT (represented in the image).

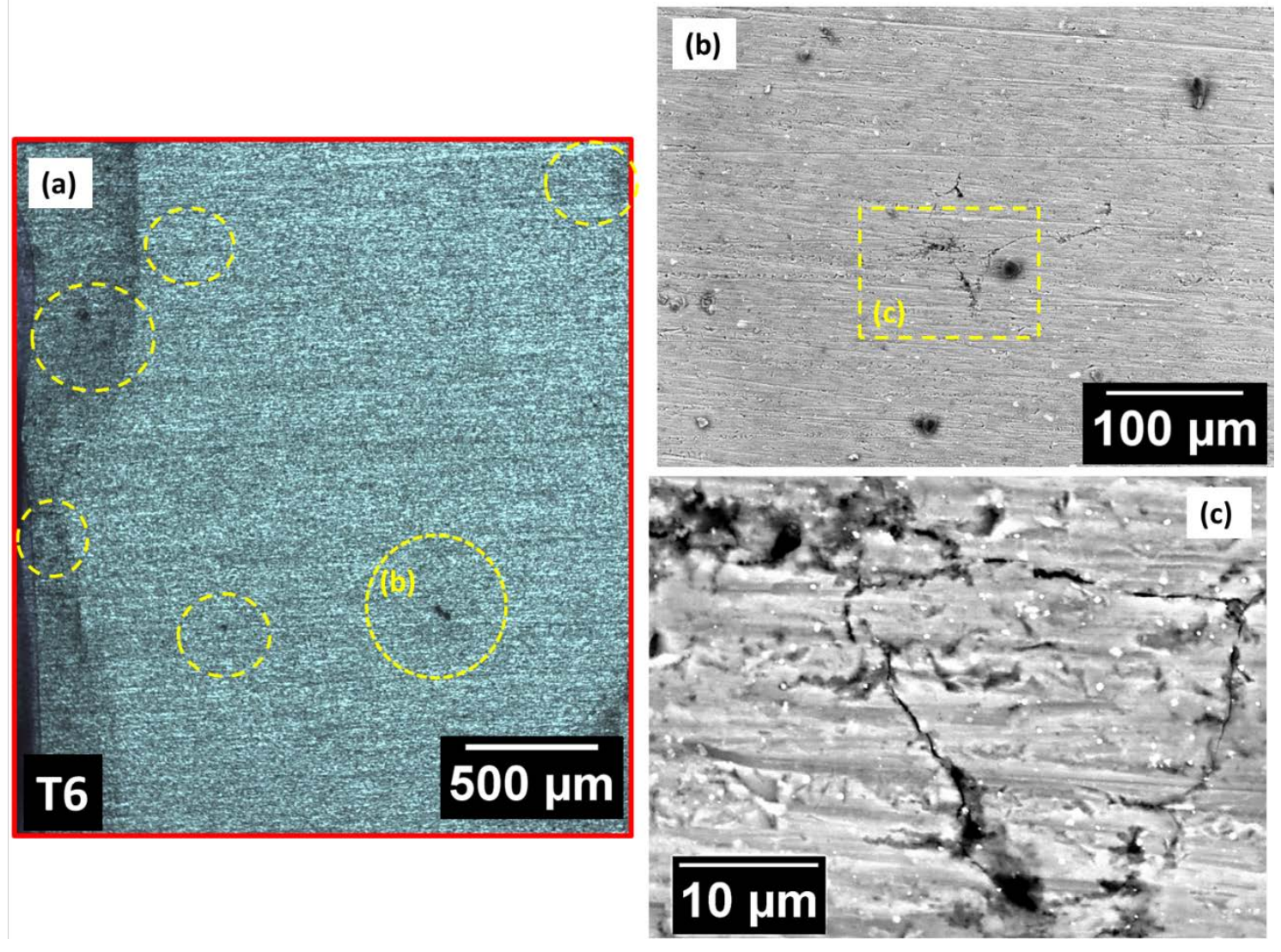

Figure 4 - (a) Optical micrograph of the exposed isolated 6061-T6 sample; (b) high magnification SEM image of the circled pit region; (c) high magnification SEM image of the pit region showing the intergranular corrosion propagation. 

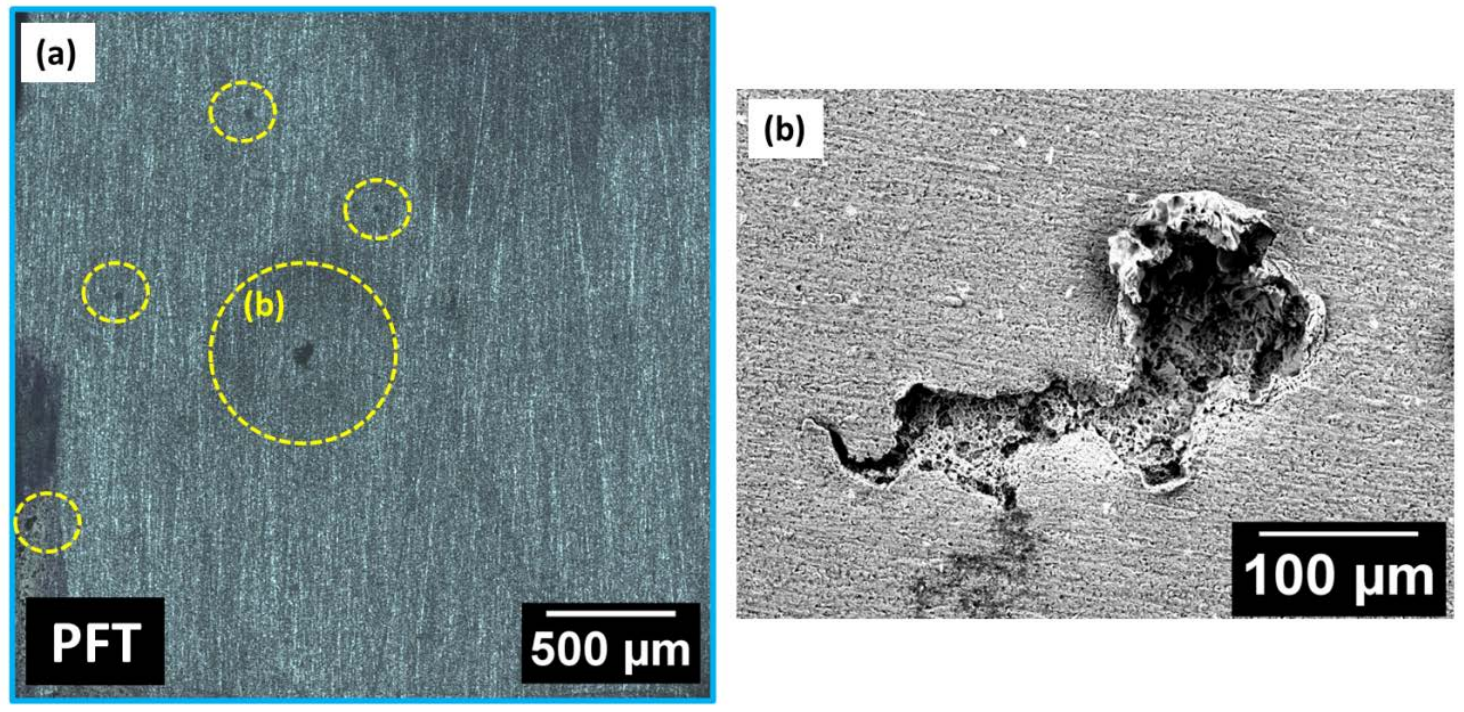

Figure 5 - (a) Optical micrograph of the exposed isolated 6061 alloy after the picture frame technique (PFT) process; (b) high magnification SEM image of the circled pit region showing the intragranular corrosion propagation.
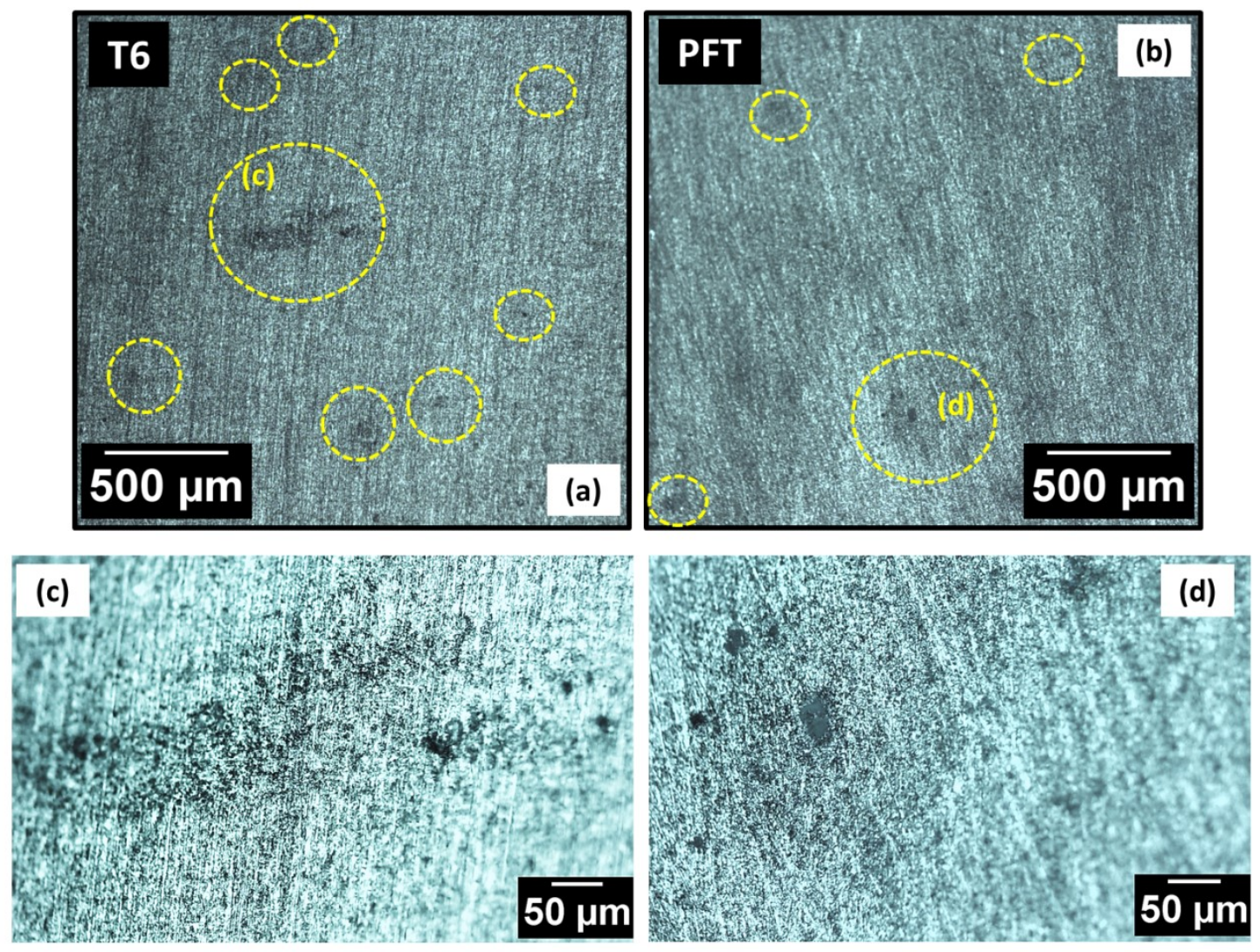

Figure 6 - $(a-b)$ Optical micrograph of the exposed surface of the (a) coupled T6 and (b) coupled PFT samples. $(c-d)$ High magnification images of the pit region for the (c) coupled T6 and (d) PFT samples. 

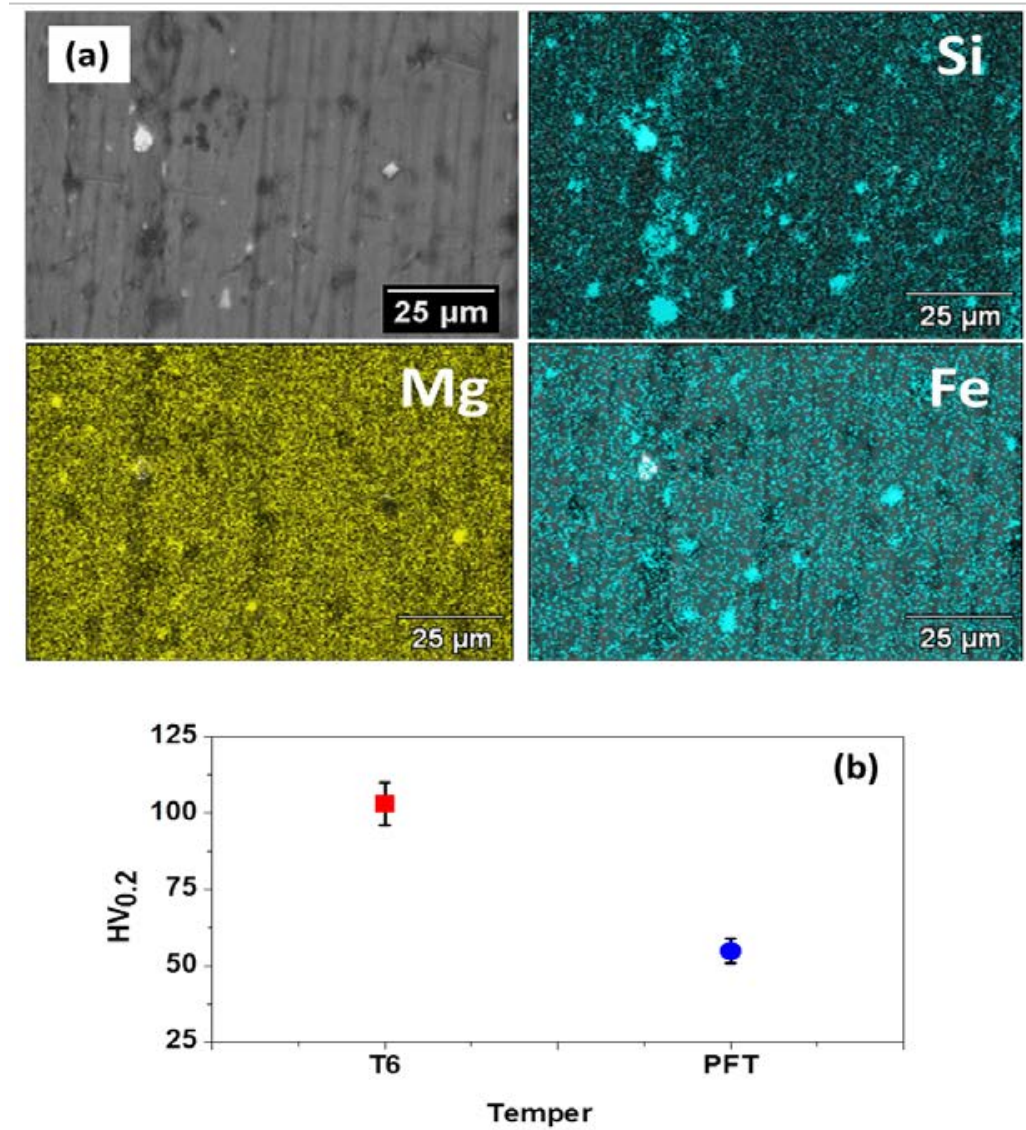

Figure 7 - (a) EDX maps of the 6061 alloy showing the chemical composition of the micrometric particles; (b) microhardness values for the 6061-T6 and picture frame technique (PFT) temper samples.

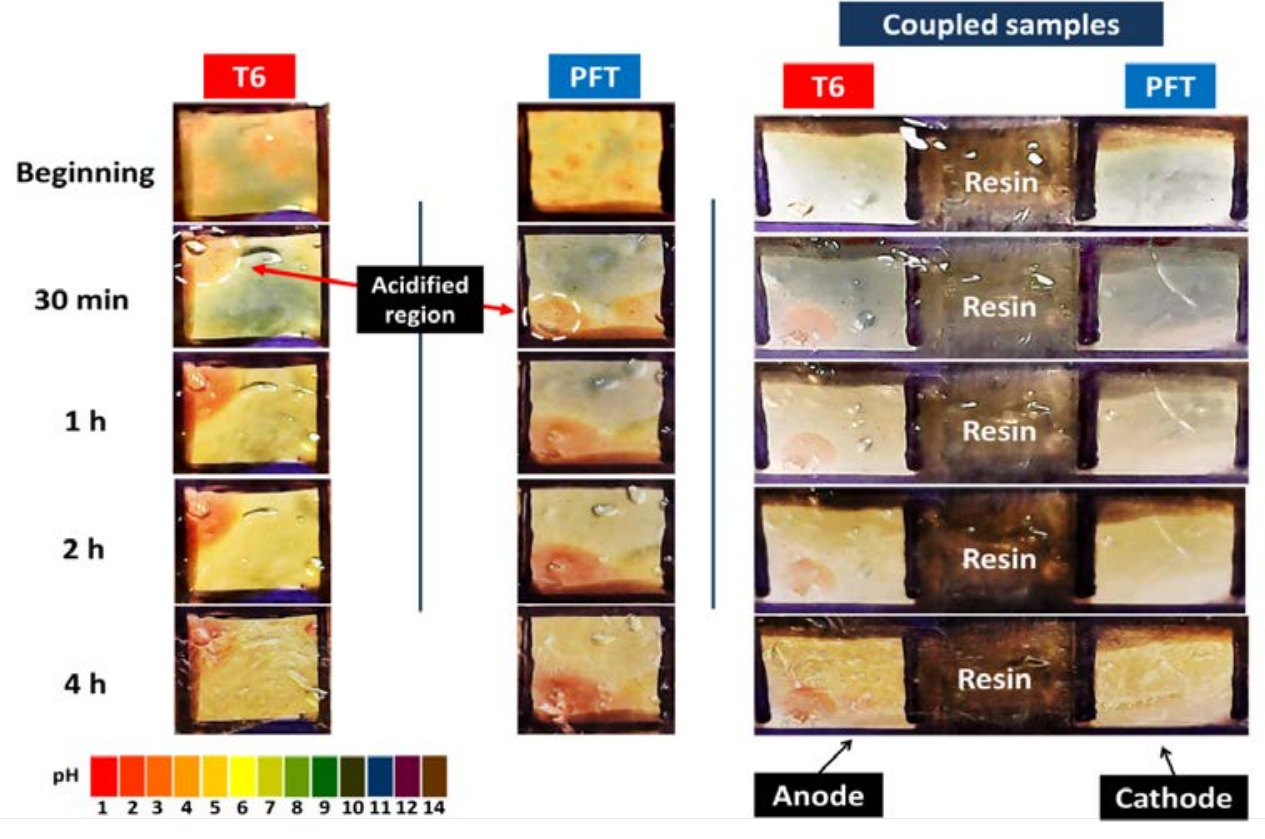

Figure 8 - Optical macrographs obtained while monitoring the exposed surfaces of the T6 sample, PFT sample and T6/PFT coupled samples in agar gel containing $0.6 \mathrm{~mol} \mathrm{~L}^{-1}$ of $\mathrm{NaCl}$ for $4 \mathrm{~h}$. 

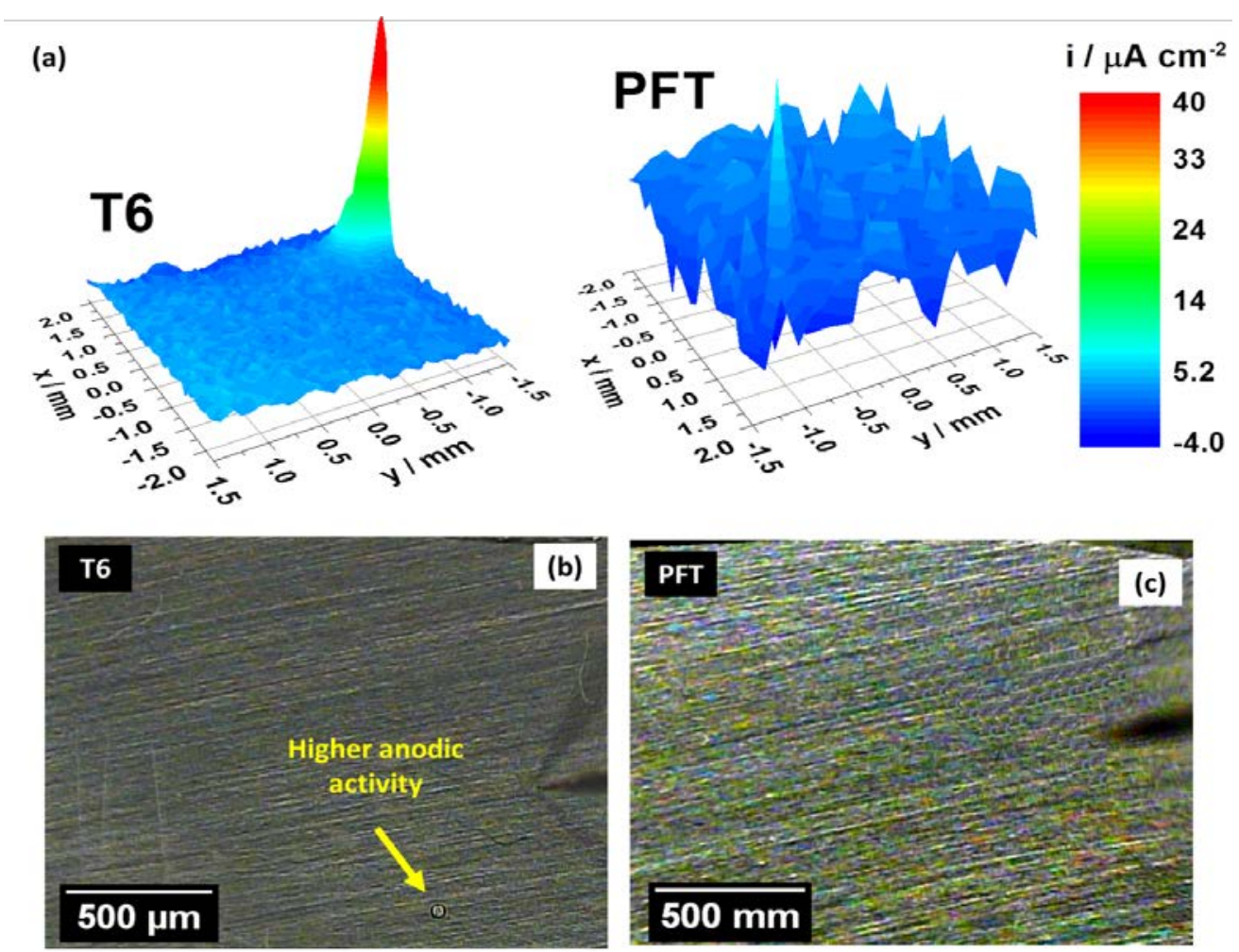

Figure 9 - (a) SVET maps of the coupled T6 / PFT samples after $2 \mathrm{~h}$ immersion in $0.05 \mathrm{~mol} \mathrm{~L}^{-1} \mathrm{NaCl}$ solution; (b-c) Optical micrographs corresponding to the T6 and PFT exposed surfaces respectively.

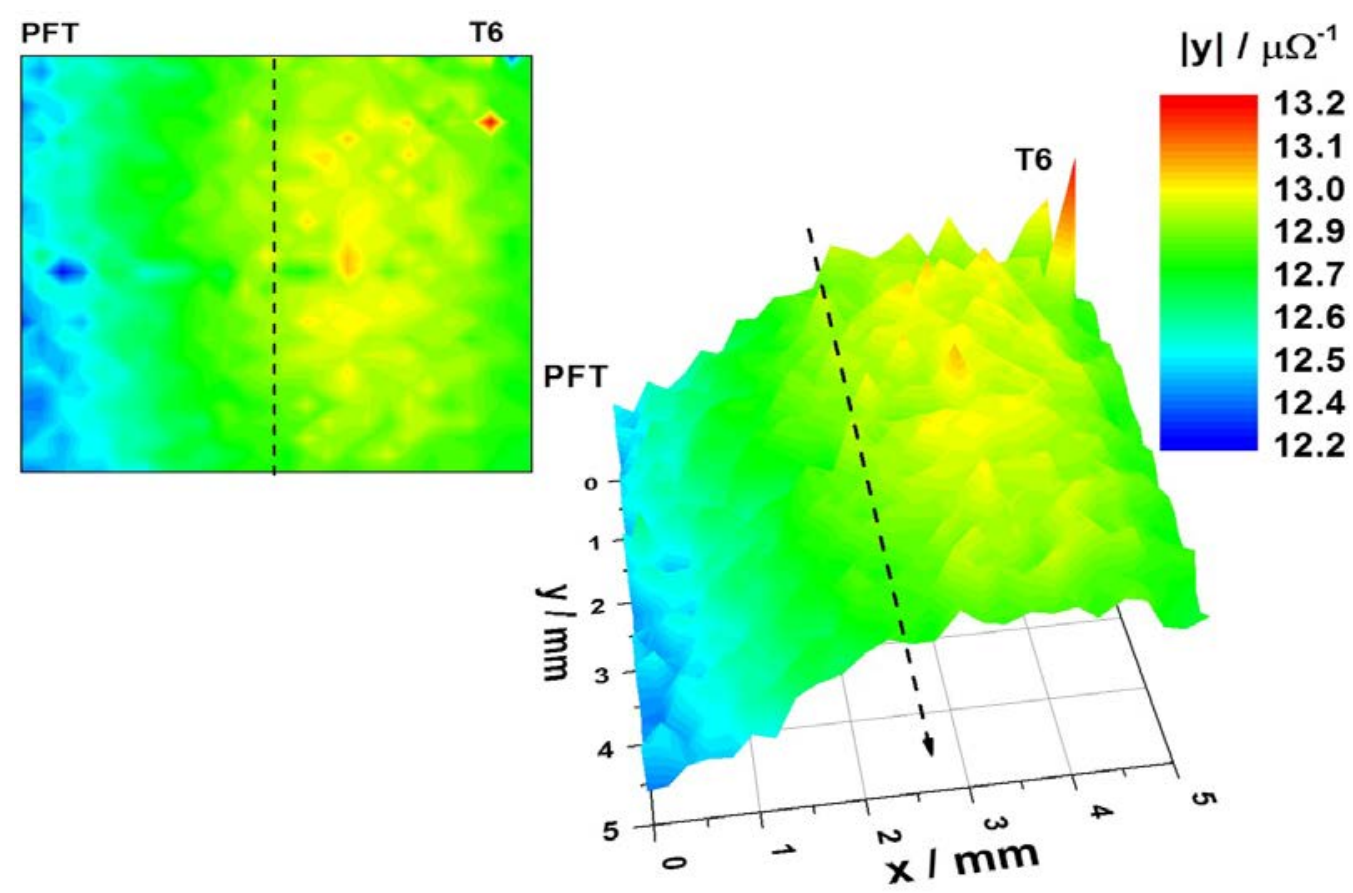

Figure 10 - Local admittance maps of the coupled T6 / PFT samples after $2 \mathrm{~h}$ immersion in $0.005 \mathrm{~mol}$ $\mathrm{L}^{-1} \mathrm{NaCl}$ solution. The dashed black line indicates the coupling region. Acquisition frequency: $5 \mathrm{~Hz}$. 

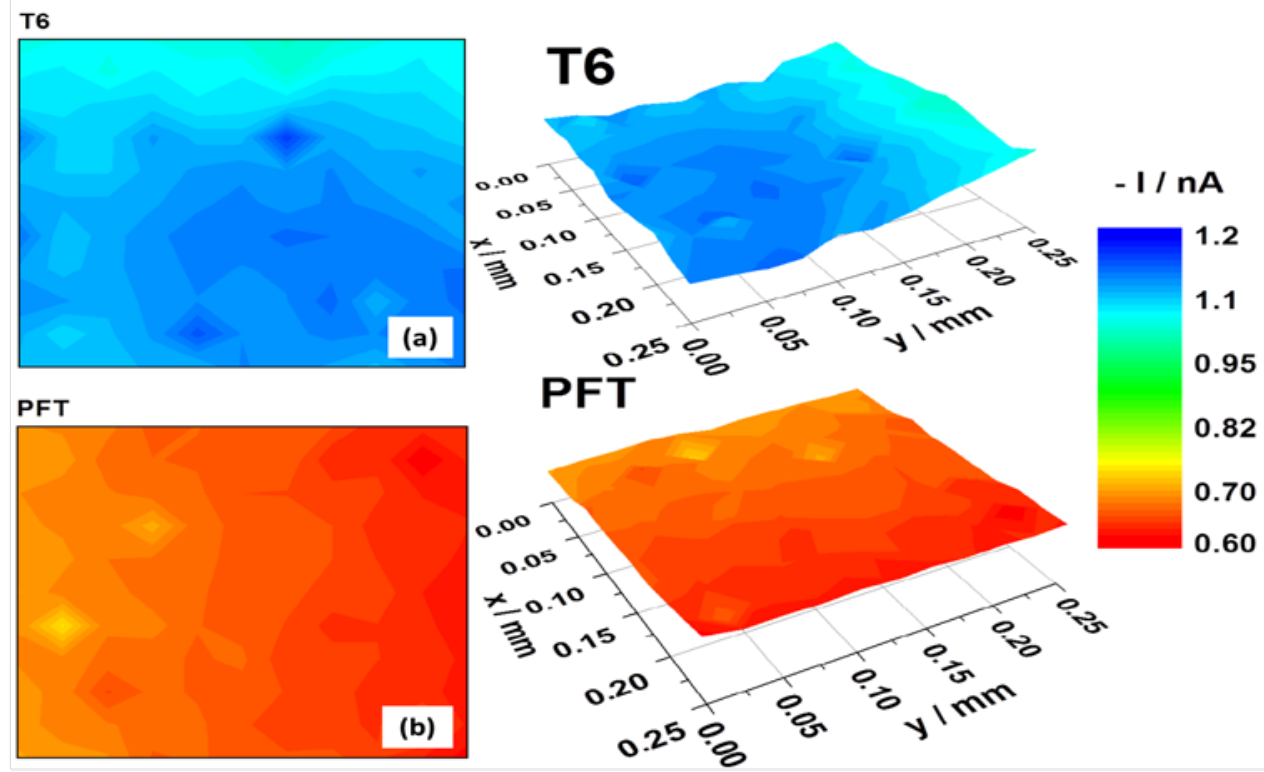

Figure 11 -SECM maps of the coupled T6 / PFT 6061 alloy obtained after $2 \mathrm{~h}$ immersion in 0.05 $\mathrm{mol} \mathrm{L}^{-1} \mathrm{NaCl}$ solution above $20 \mathrm{Dm}$ from each alloy surface with a scan rate of $50 \mathrm{Dm} \mathrm{s}$. Selected area above (a) T6 alloy; (b) PFT alloy.

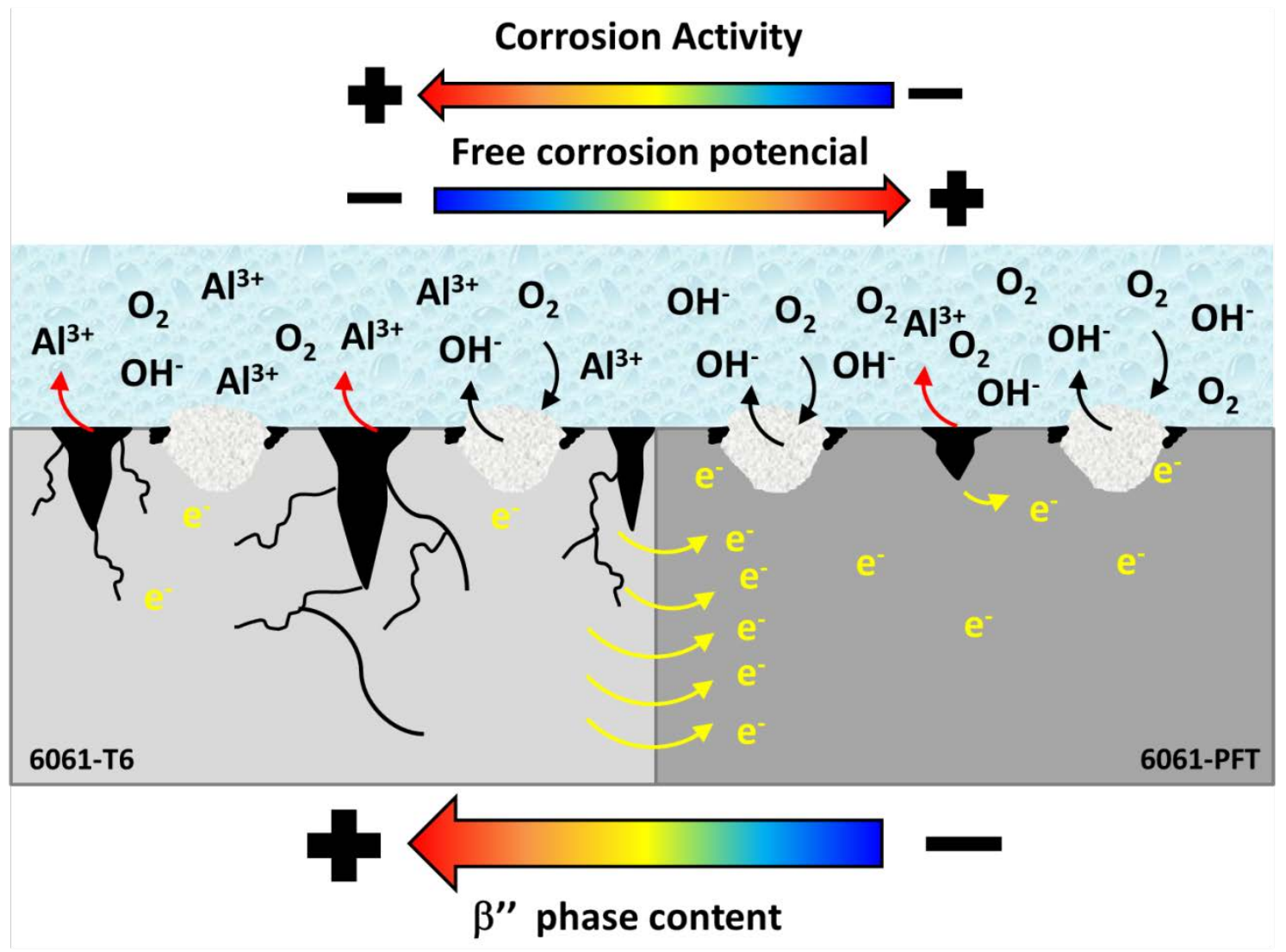

Figure 12 - Schematic diagram of the corrosion process associated with the galvanic coupling between the 6061-T6 and 6061-PFT alloys 